\title{
Viremia and effect of fetal infection with porcine viruses with special reference to porcine circovirus 2 infection
}

\author{
Maurice B. Pensaert ${ }^{\mathrm{a}, *}$, Romeo E. Sanchez, Jr. ${ }^{\text {a }}$, Anne-Sofie Ladekjær-Mikkelsen ${ }^{\mathrm{b}}$, \\ Gordon M. Allan ${ }^{\mathrm{c}}$, Hans J. Nauwynck ${ }^{\mathrm{a}}$ \\ ${ }^{a}$ Laboratory of Virology, Faculty of Veterinary Medicine, Ghent University, Salisburylaan 133, B-9820 Merelbeke, Belgium \\ ${ }^{\mathrm{b}}$ Danish Institute for Virus Research, Lindholm, D-4711 Kalvehave, Denmark \\ ${ }^{\mathrm{c}}$ Virology Section, Veterinary Sciences Division, DARDNI, Stoney Road, Stormont, Belfast BT4 3SD, UK
}

\begin{abstract}
This publication reviews some pathogenetic features of the transplacental infection with porcine viruses in sows. Viremia either with virus freely circulating or associated to peripheral blood mononuclear cells (PBMC) is an essential part of such pathogenesis. Virus replication occurs either in fetal tissues only or both in fetal and maternal tissues and the outcome may be different.

Since porcine circovirus 2 (PCV2) has been associated with reproductive failure in sows, the question was asked what type of viremia PCV2 causes and what the effect of PCV2 is on the pregnant uterus. Seronegative gilts were oronasally inoculated and plasma and PBMC were monitored for infectious virus and for quantity of viral DNA copies. Infectious virus was found in plasma only at 21 days post-inoculation (DPI). Virus associated to PBMC was detected between 14 and 49 DPI. Viral DNA was found in plasma between 14 and 49 DPI and associated to PBMC between 7 and 63 DPI (end of experiment). Direct intra-fetal inoculation at 57, 75 and 92 days of gestation and collection of fetuses 21 days later showed that the virus replicates highly in fetal tissues, particularly in the heart. Fetal death occurred in the 57 days sows while virus and antibodies were observed in the 75- and 92-day inoculated sows. Inoculation at 57 and 75 days of gestation and collection of the piglets at the end of pregnancy showed that intrauterine spread had occurred to fetuses adjacent to the inoculated ones and that fetal death occurred also in the presence of antibodies. The pregnancy was not interrupted.

This study shows that PCV2 causes viremia which is largely cell-associated and that virus replication in fetuses causes fetal death with mummification. Whether such transplacental infection occurs in the immune sow population is questionable.
\end{abstract}

(c) 2003 Elsevier B.V. All rights reserved.

Keywords: Porcine circovirus type 2; Viremia; Sows; Fetus

\section{Introduction}

In the present communication, transmission from the sow to the litter is meant to be vertical (or transpla-

\footnotetext{
* Corresponding author. Tel.: +32-9-264-73-66; fax: +32-9-264-74-95.

E-mail address: maurice.pensaert@rug.ac.be (M.B. Pensaert).
}

cental) and not horizontal. Transplacental infections with different viruses do regularly occur in sows and the pathogenesis and outcome with each of them may be quite variable.

Classical swine fever virus (CSFV), porcine reproductive and respiratory syndrome virus (PRRSV), porcine parvovirus (PPV), porcine enteroviruses (PEV), encephalomyocarditis virus (EMCV) and 
Aujeszky's disease virus (ADV) are known to be able to cross the placental barrier. In every of these cases, vertical transmission is a consequence of an initial primary infection in the sow followed by viremia. In the viremic mother, the virus spreads from the maternal circulation to fetal tissues. Whether viremia will eventually lead to transplacental spread or not, depends on many factors. Mechanisms by which the virus crosses the placenta are poorly known.

The present communication will first give some generalities on the pathogenesis of transplacental infections with porcine viruses in sows. Next, some of these features will be applied to porcine circovirus (PCV2) infection.

\section{Viremia}

Viremia is an essential part preceding the crossing of the placental barrier. It can occur as cell-free circulating virus or as virus which is cell-associated or both.

\subsection{Cell-free circulating virus}

With some virus infections, virus is freely circulating in plasma and crossing of the placental barrier is a matter of chance. This appears to be the case with PEV, PPV, EMCV and PRRSV. The chance that transplacental infection occurs may increase when high virus quantities are present and when the duration of viremia is long-lasting. Also, the blood circulation in the pregnant uterus markedly increases towards the later stages of pregnancy and, therefore, the chance that transplacental infection occurs increases as pregnancy proceeds. With the very small viruses such as PEV, PPV or EMCV, spread from the maternal to the fetal tissue may merely be a physical process. With viruses which are freely circulating in the blood of the mother, previous induction of circulating humoral immunity based on neutralizing antibodies (e.g. PPV, PEV, EMCV) efficiently stops such viremia. Therefore, sows which are immune after infection or which have antibodies in the blood after vaccination, are fully protected against transplacental spread upon (re)exposure to the field virus.

Some freely circulating viruses, such as PRRSV, may, however, have a mechanism to escape such immunity in sows vaccinated with inactivated vaccines or even in sows which were recently vaccinated with live vaccine(s) because neutralizing antibodies are either absent, low or appear rather late. Lack of neutralizing antibodies at 30 days after vaccination was an explanation why viremia was not prevented in sows after challenge with virulent virus and why transplacental spread still occurred (Mengeling et al., 1999). It was found, however, that at that time of challenge, vaccination had markedly reduced the viremia and the chance for transplacental spread.

\subsection{Cell-associated viremia}

Other viruses, such as ADV and CSFV, cause viremia which may be cell-free but which is also cell-bound or cell-associated. These viruses may enter the peripheral blood mononuclear cells (PBMC) of the mother at the primary replication site. They may or may not replicate in PBMC but these cells are carriers of infectious virus in the blood. Such viruses can, through direct cell-to-cell spread, grow their way from the maternal circulation through the placental barrier to the fetus without coming in contact with humoral immunity. In such cases, transplacental spread may not be entirely halted by specific antibodies which often do not eliminate the cell-associated virus. ADV is a typical example. Sows that have been administered once with an inactivated vaccine may, upon exposure to a high dose of field virus, still experience virus replication at the primary site of infection allowing the virus to enter PBMC and to be carried towards the uterine microcirculation. Here, direct cell-to-cell spread to fetal tissues may occur (Nauwynck and Pensaert, 1992). This way, the virus can reach fetal tissues, replicate extensively and cause abortion. A similar mechanism has been described in pregnant sows which had been vaccinated with inactivated CSFV vaccines and which, upon exposure to CSFV, underwent transplacental infection. They are the so-called "carrier sows" (Van Oirschot and Terpstra, 1989). Even though the cell-associated spread with CSFV is not as well documented as it is with $\mathrm{ADV}$, it is known that mononuclear cells are able to support pestivirus replication. In both these examples, transplacental spread occurred in sows vaccinated with inactivated vaccines and less or not in sows 
vaccinated with live vaccines or in infection-immune sows, indicating that cell-mediated immune mechanisms play an important role to avoid or eliminate cell-associated viremia.

\section{Effect of viruses on the pregnant uterus after transplacental infection}

With some viruses, transplacental infection leads to replication only in fetal tissues with no involvement of maternal tissues. Lesions are only observed in fetuses with or without fetal death. Fetal death followed by mummification is observed when infection occurs prior to fetal immunocompetence $( \pm 70$ days of gestation). Infection after fetal immunity has developed, often allows the fetus to build up antibodies and survive. The effect on the continuation of the pregnancy depends on how many fetuses have become infected during the maternal viremia, how quickly the virus spreads intra-uterinely from infected fetuses to non-infected fetuses and how many fetuses remain alive. PEV and PPV cross the placenta at any stage of pregnancy and spread rather slowly in the uterus. The pregnancy continues until the end or is prolonged. The litter consists of mummified fetuses or autolyzed piglets (with antibodies) and/or live vital piglets with antibodies and/or live piglets which have not been infected in the uterus. PRRSV and EMCV, which cause preferential transplacental infection late in pregnancy (>90 days), spread rather rapidly inside the uterus so that the effect on the pregnancy can be late-term abortion (107-110 days), premature farrowing (110-113 days) or farrowing at term. Uterine contents consist of stillbirths, autolyzed normal sized pigs, weak pigs or live and vital pigs.

With some viruses, however, replication does not only occur in fetal tissues but also in maternal uterine tissues. This is the case with ADV causing both fetal damage and endometritis. Generally, abortion occurs rather rapidly after the virus has crossed the placenta. With CSFV, abortion can occur with strains of high virulence, not only due to infection of maternal uterine tissues but also to disease (high fever) of the mother. Low virulent strains of CSFV cause congenital disorders (tremor) and birth of live and immunotolerant pigs.

\section{PCV2 infection and reproductive features in sows}

\subsection{Literature}

Recently, PCV2 has been added to the list of viruses which may cause transplacental infection in sows. Three initial reports have described the isolation of PCV2 from affected fetuses. The first report came from Canada (West et al., 1999) where PCV2 was isolated from a litter of aborted piglets from a newly established farm stocked entirely with first parity gilts and experiencing late-term abortions and stillbirths. PCV2 was detected in the myocardium and in other organs of piglets while other feto-tropic porcine viruses were excluded.

The second report came from Denmark (LadekjærMikkelsen et al., 2001a), where a field case was described in which PCV2 was isolated from a litter of 10 dead piglets ( 1 mummy, 8 late-term and 1 stillborn) in a specific pathogen-free (SPF) herd which had been free from PCV2 but which apparently had become infected. The sow farrowed on day 121 post-breeding. Samples from the piglets contained PCV2 antigen and antibodies. Following this diagnosis, a serologic examination revealed that, indeed, all animals in the herd had become positive for PCV2 antibodies concomitantly with the field case of fetal death. Reproductive problems in the herd remained limited to one sow.

A third report described the detection of PCV2 in several stillborn and nonviable neonatal piglets from a newly established sow facility containing 3000 gilts in Canada (O'Connor et al., 2001). When farrowing started in this herd, there was a high rate of reproductive losses due to an increase in the proportion of mummified fetuses (15\% during an 8-week period), increased number of stillbirths (8\%), increased pre-weaning mortality (11\%) and a slight increase of late-term abortions. PCV2 antigen was demonstrated in myocardial lesions and the virus isolated from affected hearts or pooled lung and spleen tissue of stillborns and some neonatal piglets. However, PPV was also demonstrated in the lungs of mummified fetuses and EMCV antibodies were also detected in thoracic fluid of stillborns. Moreover, by polymerase chain reaction (PCR) some stillborns and neonates were shown to be positive for PRRSV. The total clinical picture in this farm may, therefore, have been the 
result of multiple infections in which the exact role of PCV2 could not be determined. Only PCV2 was associated with myocardial lesions. It was concluded that the introduction of gilts which are seronegative to PCV2 may be important for feto-pathology to occur.

A retrospective study was performed in Canada to associate PCV2 with reproductive failure in pigs (Bogdan et al., 2001). Tissues of piglets collected between 1995 and 1998 from routine submissions involving reproductive failure were examined for PCV2 by PCR and immunohistochemistry. Neither PCV2 nor PCV1 was detected. It was suggested, however, that there may have been some bias in the samples tested because of the relative under-representation of cardiac tissue in the available archival material examined. In the two previous reports of PCV2-associated reproductive failure, PCV2 was consistently linked with cardiac lesions. Further, because the above study met with negative results, the authors suggested that the recently reported cases of PCV2-associated reproductive disease may represent a newly acquired clinical manifestation of this virus.

\subsection{Own experiments on viremia and feto-pathology in PCV2-inoculated sows}

We performed a number of experiments with PCV2 which were meant to answer the following questions:

- does PCV2 cause viremia (free in plasma or bound to PBMC) in adult seronegative gilts and, if so, what is its duration and extent;

- once PCV2 has entered the fetuses, what are the events occurring with regard to:

$\circ$ fetal pathology at different gestation stages,

- possible immune response in fetuses,

o intrauterine spread of the virus,

o influence on the course of pregnancy.

\subsubsection{Viremia}

Four SPF, non-pregnant gilts, 8 months of age and seronegative for PCV2 antibodies were oronasally inoculated with $10^{5}$ TCID $_{50}$ of the PCV2 strain which was isolated from the litter of dead fetuses in Canada (designated 1121; West et al., 1999). The virus stock used in the experimental inoculations was at the fourth passage level in PK15 cells with a titer of
$10^{6} \mathrm{TCID}_{50} / \mathrm{ml}$. Heparinized blood was collected at $0,2,5$ and 7 DPI and further at weekly intervals between 7 and 63 DPI. Plasma and PBMC were separated and individually examined for infectious virus. For this purpose, $10^{7}$ PBMC in $500 \mu$ l were freeze-thawed three times and subsequently, $50 \mu \mathrm{l}$ of each cell suspension were diluted 10 -fold in culture medium and inoculated into semi-confluent monolayers of PCV-free PK15 cells in 96-well microtiter plates. Plasma samples were likewise diluted 10-fold in medium and inoculated in PCV-free PK15 cells. After $1 \mathrm{~h}$ of incubation at $37^{\circ} \mathrm{C}$, the inoculum was replaced with fresh medium and further incubated for $72 \mathrm{~h}$. Thereafter, the cells were fixed and stained for PCV2 antigens using a PCV2 mouse monoclonal antibody (F217) (McNielly et al., 2000) and goat-anti-mouse peroxidase. Plasma samples collected from the four gilts at each of 10 time points (Fig. 1) were pooled and each pool was inoculated intramuscularly into one seronegative pig of 16 weeks old to detect possibly low quantities of PCV2 (pig inoculation). Lyzed PBMC collected at each of 12 time points (Fig. 2) were pooled and each pool was inoculated intramuscularly into one seronegative pig. All inoculated pigs were followed for seroconversion at 28 days after inoculation.

Also, all individual plasma and PBMC samples were tested by quantitative PCR in the Danish Veterinary Institute for Virus Research (Ladekjær-Mikkelsen et al., 2001b). Antibody tests were performed using the immuno-peroxidase monolayer assay (IPMA) (Labarque et al., 2000). All four gilts seroconverted to PCV2 starting at 21 DPI (Table 1). PCV1 antibodies were not detected.

Table 1

Mean antibody titers in four gilts at selected time points after inoculation with PCV2

\begin{tabular}{lcc}
\hline $\begin{array}{l}\text { Days post- } \\
\text { inoculation }\end{array}$ & \multicolumn{2}{l}{$\begin{array}{l}\text { IPMA antibody titers } \\
\text { (geometric mean) against }\end{array}$} \\
\cline { 2 - 3 } & PCV2 & PCV1 \\
\hline 0 & $<20$ & $<20$ \\
7 & $<20$ & $<20$ \\
14 & $<20$ & $<20$ \\
21 & 160 & $<20$ \\
28 & 3,620 & $<20$ \\
35 & 20,480 & $<20$ \\
42 & 17,222 & $<20$ \\
\hline
\end{tabular}


Mean virus titre

$\left(\log _{10} \mathrm{TCID}_{50} / \mathrm{ml}\right.$

$<0.8<0.8<0.8<0.8$

$<0.8$

$<0.8$

$<0.8$

$<0.8$

$<0.8$

$<0.8$

$<0.8$

$<0.8$

plasma) as determined

in PK-15 cells

\begin{tabular}{l}
$\begin{array}{l}\text { Infectious virus by pig } \\
\text { inoculation } \\
\text { (seroconversion) }\end{array}$ \\
\hline
\end{tabular}

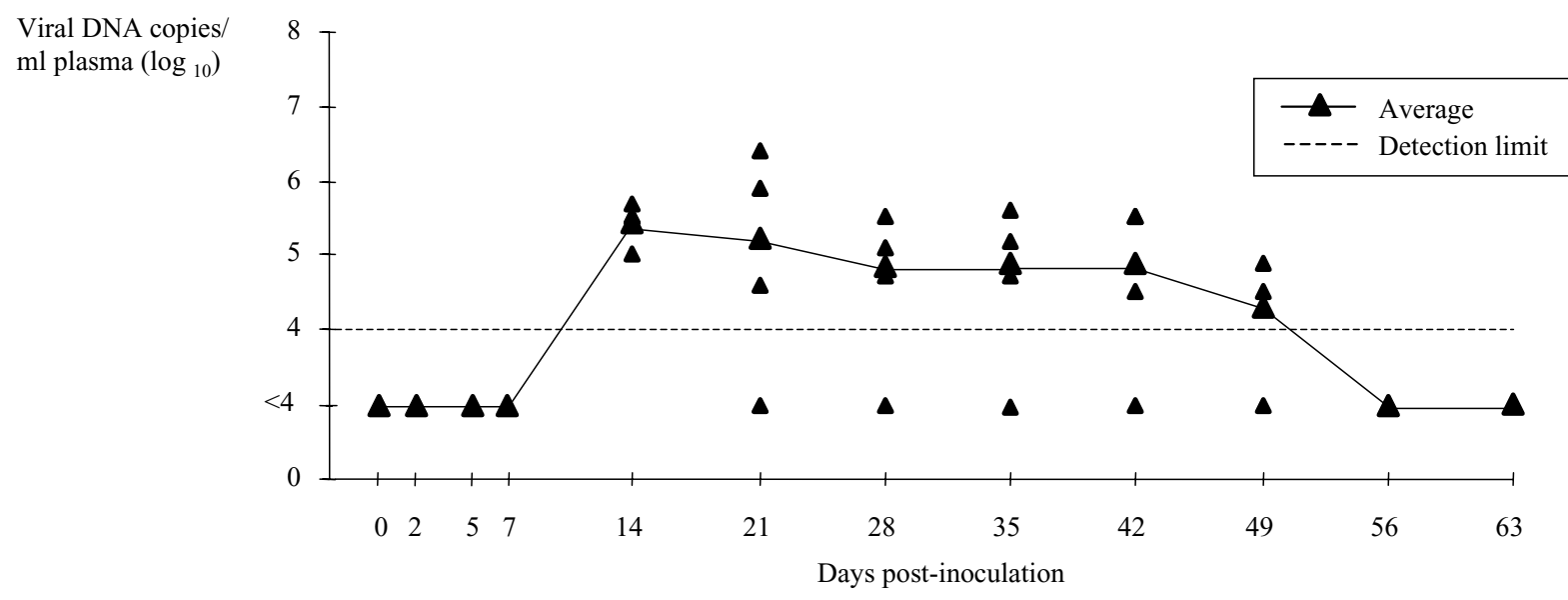

NT : not tested

Fig. 1. Examinations for infectious virus and viral DNA in plasma of gilts collected at different time points after PCV2 inoculation.

\begin{tabular}{|c|c|c|c|c|c|c|c|c|c|}
\hline $\begin{array}{l}\text { Mean virus titre } \\
\left(\log _{10} \mathrm{TCID}_{50} / 10^{7}\right. \\
\text { PBMC) as determined } \\
\text { in PK-15 cells }\end{array}$ & $<0.8<0.8<0.8<0.8$ & $<0.8$ & $<0.8$ & $<0.8$ & 1.0 & $<0.8$ & $<0.8$ & $<0.8$ & $<0.8$ \\
\hline $\begin{array}{l}\text { Infectious virus by } \\
\text { pig inoculation } \\
\text { (seroconversion) }\end{array}$ & $-\quad-\quad-\quad-$ & + & + & + & + & + & + & - & - \\
\hline
\end{tabular}

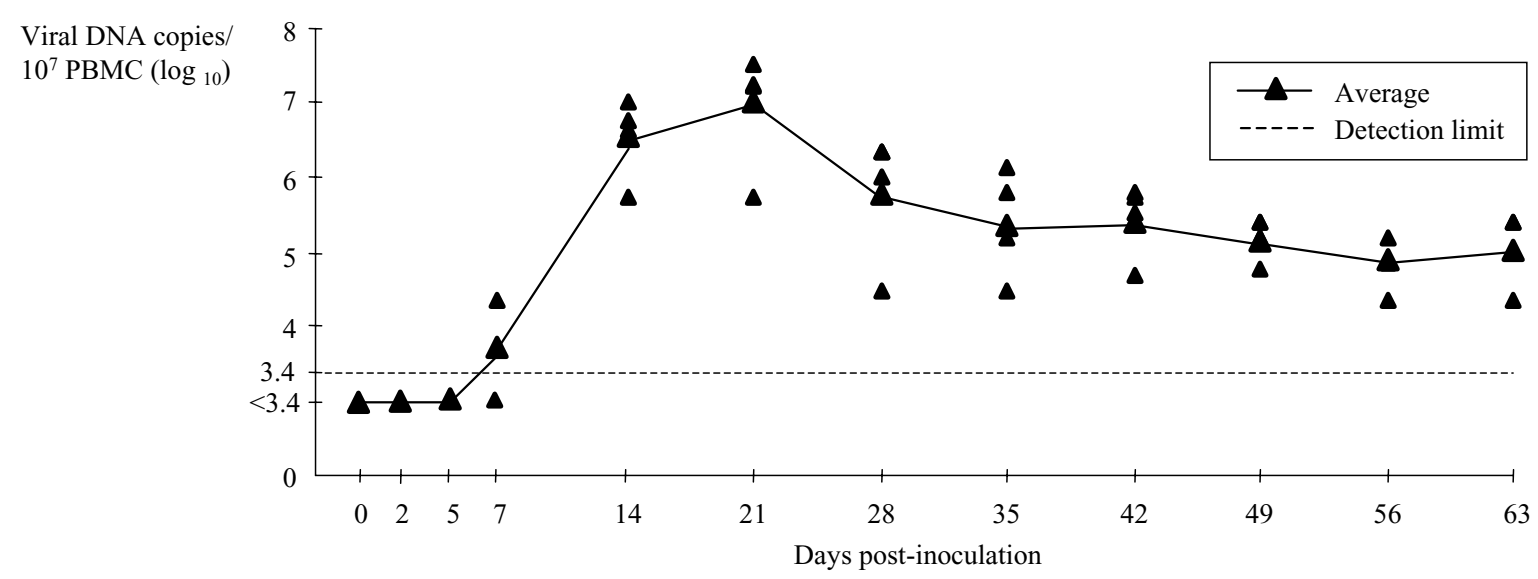

Fig. 2. Examinations for infectious virus and viral DNA in peripheral blood mononuclear cells (PBMC) of gilts collected at different time points after PCV2 inoculation. 
The results of the virus titration in cell cultures, detection of infectious virus by pig inoculation and the results of quantitative PCR are presented in Fig. 1 for the plasma samples and Fig. 2 for the PBMC samples. All inoculated plasma samples were negative by virus isolation in cell culture. By pig inoculation, only the pooled plasma sample at 21 DPI was positive. By $\mathrm{PCR}$, all plasma samples were positive in three of the four gilts between 14 and 49 DPI while in one gilt viral DNA was detected only at 14 DPI. Individual PBMC samples were positive in cell cultures only in two of the four gilts at 35 DPI. By pig inoculation, pooled PBMC samples were positive from 14 days until 49 DPI. By PCR on lyzed PBMC, one of four gilts were positive at 7 DPI. From 14 days until the end of the experiment (63 days), all gilts were positive. It was concluded from these experiments that infectious virus was present in the blood until at least 49 days after inoculation. Viremia appeared to be cell-free and cell-associated but the cell-associated form was much more prominent and long-lasting. Therefore, conditions for a potential spread of PCV2 from the blood of the mother were fulfilled. There were more samples positive by PCR than by pig inoculation but the comparative study showed that PCR-positivity does not represent infectivity.

The significance of the PBMC-associated viremia is not clear. It was of interest that the cell-associated viremia was present concomitantly with IPMA antibodies. It is possible that these antibodies had reduced or eliminated cell-free virus and that, therefore, cell-associated virus was more prominent. But this is rather unlikely since infectious virus was also not detected in plasma prior to the appearance of antibodies.

As viremia with PCV2 is cell-associated, it is interesting to determine if it still can occur in immune animals upon re-exposure. PCV2 is ubiquitous and all animals on conventional farms are seropositive at the time of sexual maturity (Labarque et al., 2000; Sanchez et al., 2001a,b). It will, therefore, be useful to examine whether re-infection with PCV2 in immune sows is still able to cause viremia, possibly in cell-associated form.

It has been postulated that different PCV2 isolates may possibly show differences in invasiveness towards the placenta and differences in feto-pathology. It could, therefore, be interesting to test different iso- lates for their ability to cause cell-associated viremia in immune sows.

\subsubsection{Effect of PCV2 infection on fetuses at different stages of gestation}

4.2.2.1. PCV2 inoculated fetuses collected at 21 days after inoculation. A series of experiments was subsequently done to examine the effect of the virus on the pregnant uterus once it has been introduced in fetuses by direct inoculation transplacentally (Sanchez et al., 2001b). In these experiments, we were obliged to use naturally immune sows since no seronegative animals were available. Immunity of the sow, however, does not play a role in the fetus since, specific immune factors do not cross the placental barrier from the mother towards the fetus during pregnancy (Tizard, 1996). In the present experiments, two fetuses were inoculated in utero in each of two sows at 57, 75 and 92 days of gestation, respectively. Inoculation occurred across the uterus after laparotomy. The same strain and stock of PCV2 used for the viremia studies was utilized. The virus was directly introduced into the peritoneal cavity $(0.1 \mathrm{ml})$ and the amniotic sac $(0.1 \mathrm{ml})$. One fetus was mock-inoculated with phosphate buffered saline. The sites of the uterus where fetuses had been inoculated were individually marked by a suture for later identification. Twenty-one days after inoculation, the sows were euthanatized and the fetuses were collected and examined for virus by isolation in PK15, for antibodies by IPMA and for gross lesions. All mock-inoculated and uninoculated fetuses were normal, virus negative and antibody negative.

The results of the virus and antibody titrations in virus-inoculated fetuses are presented in Table 2. Fetuses inoculated at 57 days of gestation had the highest virus titers and no antibodies. Antibodies and lower virus titers were detected in fetuses inoculated at 75 and 92 days of gestation. The highest virus titers were obtained from the heart, lungs and liver.

Gross lesions characterized by edema, hemorrhages and congestion were observed in all four fetuses inoculated at 57 days of gestation. Gross abnormalities were not observed in the fetuses inoculated at 75 and 92 gestational days.

These experiments showed that once PCV2 has entered fetuses, replication occurs in several fetal tissues but mainly in the heart which most likely serves as the primary target organ. When fetuses were infected 
Table 2

Virus titers in selected organs, antibody titers and gross lesions in fetuses 21 days after intra-fetal inoculation with PCV2 at different stages of gestation

\begin{tabular}{|c|c|c|c|c|c|c|c|c|}
\hline \multirow{2}{*}{$\begin{array}{l}\text { Gestation days } \\
\text { at inoculation }\end{array}$} & \multirow[t]{2}{*}{ Sow } & \multirow{2}{*}{$\begin{array}{l}\text { Fetus } \\
\text { number }\end{array}$} & \multicolumn{4}{|c|}{ Virus titer $\left(\log _{10} \mathrm{TCID}_{50} / \mathrm{g}\right.$ or $\left.\mathrm{ml}\right)$} & \multirow{2}{*}{$\begin{array}{l}\text { IPMA antibody } \\
\text { titer }\end{array}$} & \multirow{2}{*}{$\begin{array}{l}\text { Gross } \\
\text { lesions }\end{array}$} \\
\hline & & & Heart & Lungs & Liver & Serum & & \\
\hline \multirow[t]{4}{*}{57} & A & 1 & 6.5 & 5.0 & 6.0 & 2.8 & $<10$ & Yes \\
\hline & & 2 & 5.7 & 3.4 & 5.5 & 2.6 & $<10$ & Yes \\
\hline & $\mathrm{B}$ & 1 & 5.7 & 3.5 & 4.7 & 2.3 & $<10$ & Yes \\
\hline & & 2 & 5.7 & 3.3 & 5.3 & 2.3 & $<10$ & Yes \\
\hline \multirow[t]{4}{*}{75} & $\mathrm{C}$ & 1 & 4.3 & 3.2 & 4.5 & $<0.8$ & 640 & No \\
\hline & & 2 & 4.5 & 3.0 & 2.0 & $<0.8$ & 640 & No \\
\hline & $\mathrm{D}$ & 1 & 5.0 & 1.7 & 4.5 & $<0.8$ & 160 & No \\
\hline & & 2 & 4.7 & 2.5 & 4.7 & $<0.8$ & 40 & No \\
\hline \multirow[t]{4}{*}{92} & $\mathrm{E}$ & 1 & 1.7 & $<1.5$ & 1.7 & $<0.8$ & 2560 & No \\
\hline & & 2 & 2.0 & 2.0 & $<1.5$ & $<0.8$ & 160 & No \\
\hline & $\mathrm{F}$ & 1 & 4.0 & 1.7 & $<1.5$ & $<0.8$ & 160 & No \\
\hline & & 2 & 3.5 & 3.7 & 3.2 & $<0.8$ & 10 & No \\
\hline
\end{tabular}

after immunocompetence ( $>70$ days), virus co-existed with antibodies. Virus titers were significantly higher in the 57-day inoculated fetuses compared to the 75and 92-day inoculated fetuses. This may reflect a higher susceptibility of younger fetuses but could also be the result of antibodies which may have interfered with the formation of high virus titers in 75- and 92-day fetuses. The absence of virus and antibodies in uninoculated fetuses at 21 DPI, shows that PCV2 does not spread rapidly in the uterus once it has entered.

Fetuses inoculated at 75 and 92 days were totally normal. It is thus possible that PCV2 replicates in fetuses with formation of antibodies but without fetal pathology. However, these experiments did not allow conclusions with regard to the effect of PCV2 infection in the fetuses on a longer term.

\subsubsection{PCV2-inoculated fetuses collected at the end} of pregnancy. In order to examine the long-term effect of the intra-fetal virus inoculation on the fetuses and on the course of pregnancy, two fetuses each were inoculated, as described above, in one sow at 57 days and in another sow at 75 days of gestation. Piglets were collected at the end of gestation either by hysterectomy at 113 days in the 57-day inoculated sow or upon natural farrowing in the 75-day inoculated sow. The piglets were examined for infectious virus in the heart (the main target organ of PCV2 replication in fetal life), antibodies and for gross pathology.

The results of examinations in the 57 days gestation sow are presented in Table 3. The two inoculated fetuses as well as the two fetuses immediately adjacent to these fetuses were positive for virus and were grossly affected. The inoculated fetuses were mummified. One of the contact-infected fetuses (no. 1) was stillborn and the other (no. 4) appeared weak. Both contact-infected fetuses had PCV2 co-existing with a low titer of antibodies.

The 75 gestation day sow farrowed so that identification of piglets which had been inoculated as fetuses was not possible. The results in this sow are presented in Table 4. Only two of the piglets in the entire litter were grossly affected (one autolyzed, one stillborn) and these piglets were also positive for virus and antibodies. Presumably, these two pigs had been inoculated as fetuses since all the other pigs were negative for virus. Virus had not spread in the uterus to uninoculated fetuses.

These experiments showed that PCV2 causes fetal pathology and death without affecting the maternal physiology or pregnancy. Fetal death was evident if fetuses were inoculated as well in mid-pregnancy as after immunocompetence. Fetuses inoculated at the time of immunocompetence may have virus, antibodies and lesions by the end of the pregnancy. Pathology 
Table 3

Virus and antibody titers in and gross appearance of piglets from a sow inoculated with PCV2 at 57 days and harvested by hysterectomy at 114 days of gestation

\begin{tabular}{lclc}
\hline Piglet number $^{\mathrm{a}}$ & Virus titer in heart $\left(\log _{10} \mathrm{TCID}_{50} / \mathrm{g}\right)$ & Gross appearance & IPMA antibody titer \\
\hline 1 & 3.5 & Stillborn & 160 \\
$2^{\mathrm{b}}$ & 4.5 & Mummified & Not tested \\
$3^{\mathrm{b}}$ & 4.0 & Mummified & Not tested \\
4 & 3.5 & Weakborn & 10 \\
$5-13$ & $<1.5$ & Normal & $<10$ \\
\hline
\end{tabular}

${ }^{\text {a }}$ Fetuses are numbered in sequence as they were located in the uterus: from base of the right horn towards its tip (1-7) and similarly for the left horn (8-13).

b PCV2 inoculated fetuses.

Table 4

Virus and antibodies titers in and gross appearance of piglets collected after farrowing from a sow inoculated with PCV2 at 75 days of gestation

\begin{tabular}{lclr}
\hline Piglet number & Virus titer in heart $\left(\log _{10} \mathrm{TCID}_{50} / \mathrm{g}\right)$ & Gross appearance & IPMA antibody titer \\
\hline $1^{\mathrm{a}}$ & 3.0 & Fresh, stillborn & 2560 \\
$2^{\mathrm{a}}$ & 3.5 & Autolyzed & 40 \\
$3-13$ & $<1.5$ & Normal & Suckled \\
\hline
\end{tabular}

a Presumably inoculated since all others were negative for virus.

in fetuses infected in utero was thus characterized by fetal death and mummification without interruption of pregnancy. In this sense, the PCV2 fetal infection very much resembles that of PPV and PEV.

The limited intra-uterine spread of PCV2 in the 57-day sow from inoculated fetuses to only those directly adjacent to these fetuses and the absence of inter-fetal spread in the 75-day sow show that PCV2 dissemination in the uterus does not occur readily. This slow spread of the virus in the uterus may have been responsible for uninterrupted progression of pregnancy. Had PCV2 spread to more fetuses in the uterus and consequently caused fetal death in these fetuses, the progression of pregnancy may have been affected. Why PCV2 spread slowly in the uterus is not known.

The finding that PCV2 was not associated with fetal pathology in the previously mentioned retrospective field study (Bogdan et al., 2001) does not mean that PCV2 transplacental infection had not occurred. Examination of full-term autolyzed and stillborn piglets for antibodies and virus in the heart could give a clearer picture on whether PCV2 is involved in reproductive problems in the field or not. Again, the question on whether viremia, possibly cell-associated, can occur in immune sows upon re-exposure, remains to be solved because this would increase the chance that PCV2 transplacental transmission can occur in the endemically infected sow population.

As a conclusion, the present results show that PCV2 causes viremia which appears to be cell-associated and which persists in the presence of early immune responses. The virus, once in contact with fetal tissues, causes fetal death with or without fetal immune response depending on the age of gestation at infection. In such fetuses, virus co-exists with antibodies. Intra-uterine virus spread occurs rather slowly.

Whether fetal infection occurs in the field remains unclear. Most of the sow population is infection-immune at sexual maturity (Labarque et al., 2000; Sanchez et al., 2001a,b). If PCV2 is able to cause viremia and escape immunity in such sows, then transplacental infection might occur.

\section{Acknowledgements}

The authors thank J. Ellis for kindly supplying the PCV2 isolate. We also acknowledge S. Van Gucht, G. Labarque and F. de Backer for their assistance during surgery and C. Bracke and V. Van Hoorde for their excellent technical assistance. R.E. Sanchez Jr. is funded 


\section{by Grant QLK2-CT-1999-00445 from the European} Union.

\section{References}

Bogdan, J., West, K., Clark, E., Konoby, C., Haines, D., Allan, G., McNeilly, F., Meehan, B., Ellis, J.A., 2001. Association of porcine circovirus 2 with reproductive failure in pigs: a retrospective study, 1995-1998. Can. Vet. J. 42, 548-550.

Labarque, G.G., Nauwynck, H.J., Mesu, A.P., Pensaert, M.B., 2000. Seroprevalence of porcine circovirus types 1 and 2 in the Belgian pig population. Vet. Quart. 22, 234-236.

Ladekjær-Mikkelsen, A.-S., Nielsen, J., Storgaard, T., Bøtner, A., Allan, G., McNeilly, F., 2001a. A field case of transplacental infection with PCV2 associated with reproductive failure. Vet. Rec. 148, 759-760.

Ladekjær-Mikkelsen, A.-S., Stadejek, T., Storgaard, T., Nielsen, J., Allan, G., Bøtner, A., 2001b. Post-weaning multisystemic wasting syndrome: quantification of porcine circovirus load by real-time PCR. In: Proceedings of the Symposium on ssDNA Viruses of Plants, Birds, Pigs and Primates, Saint Malo, France, p. 101.

McNielly, F., McNair, I., Mackie, D.P., Meean, S., Kennedy, S., Moffett, D., Ellis, J., Krakowka, S., Allan, G.M., 2000. Production, characterization and application of monoclonal antibodies to porcine circovirus 2. Arch. Virol. 146, 909-922.

Mengeling, W.L., Lager, K.M., Vorwald, A.C., 1999. Safety and efficacy of vaccination of pregnant gilts against porcine reproductive and respiratory syndrome. Am. J. Vet. Res. 60, 796-801.

Nauwynck, H.J., Pensaert, M.B., 1992. Abortion induced by cell-associated Aujeszky's disease virus in vaccinated sows. Am. J. Vet. Res. 53, 489-493.

O'Connor, B., Gauvreau, H., West, K., Bogdan, J., Ayroud, M., Clark, E.G., Konoby, C., Allan, G., Ellis, J.A., 2001. Multiple porcine circovirus 2-associated abortions and reproductive failure in a multisite swine production unit. Can. Vet. J. 42, 551-553.

Sanchez, R.E., Nauwynck, H.J., Pensaert, M.B., 2001a. Serological survey of porcine circovirus 2 antibodies in domestic and feral pig populations in Belgium. In: Proceedings of the Symposium on ssDNA Viruses of Plants, Birds, Pigs and Primates, Saint Malo, France, p. 122.

Sanchez Jr., R.E., Nauwynck, H.J., McNeilly, F., Allan, G.M., Pensaert, M.B., 2001b. Porcine circovirus 2 infection in swine foetuses inoculated at different stages of gestation. Vet. Microbiol. 83, 169-176.

Tizard, I.R., 1996. Veterinary Immunology: An Introduction. Saunders, Pennsylvania, pp. 237-250.

Van Oirschot, J.T., Terpstra, C., 1989. Hog cholera virus. In: Pensaert, M.B. (Ed.), Virus Infections of Porcines. Elsevier, Amsterdam, pp. 113-130.

West, K.H., Bystrom, J.M., Wojnarowicz, C., Shantz, N., Jacobson, M., Allan, G.M., Haines, D.M., Clark, E.G., Krakowka, S., McNeilly, F., Konoby, C., Martin, K., Ellis, J.A., 1999. Myocarditis and abortion associated with intrauterine infection of sows with porcine circovirus 2. J. Vet. Diagn. Invest. 11, $530-532$. 